Kastamonu Eğitim Dergisi
$\begin{aligned} & \text { Kastamonu Education Journal } \\ & \text { Ocak 2020 Cilt:28 Sayı:1 } \\ & \text { kefdergi.kastamonu.edu.tr }\end{aligned}$

\title{
Bilgi Yönetimi Eğilimi Ölçeğinin Türkiye Kültürüne Uyarlanması: Geçerlik ve Güvenirlik Çalışması
}

\section{Adaptation of Knowledge Management Orientation Scale into Turkish: The Study of Validity and Reliability}

\author{
Mehmet DURNALI ${ }^{1}$ \& ibrahim LIMON² \\ Öz
}

Bu çalışmanın amacı, Wang, Ahmed ve Rafiq (2008) tarafından geliştirilen Bilgi Yönetimi Eğilimi Ölçeği (BYE-Ö)'ni Türkiye Kültürüne uyarlamaktır. İlk olarak, ölçeğin Türkçe sürümünün dilsel eşdeğerliği İngilizce uzmanlarından oluşan bir grubun fikir birliği ile sağlanmıştır. Sonrasında, ölçeğin yapı geçerliliğini test etmek amacıyla Doğrulayıcı Faktör Analizi (DFA) için gönüllük esasına dayalı olarak 2017-2018 öğretim yılı sonunda Türkiye genelinde 206 öğretmenden veri toplanmıştır. DFA sonucuna göre; yapısal geçerliliği test edilen modelin uyum değerlerinin en az "kabul edilebilir" düzeylerde olduğu tespit edilmiştir. BYE-Ö maddelerinin bireyleri iyi derecede ayırt edebildiği tespit edilmiştir. Ölçek bütünü ve alt faktörlerin ilişki katsayısı değerleri, ölçek bütünü ve alt faktörleri arasında pozitif yönlü anlamlı doğrusal bir ilişki olduğunu işaret etmiştir. Cronbach's Alpha katsayısı; ölçeğin tamamı için .901; örgütsel hafıza alt faktörü için .845; bilgi paylaşımı alt faktörü için .712; bilgi edinimi/kavrama alt faktörü için .668 ve bilgi duyarlılığı alt faktörü için .792 bulunmuştur. DFA bu yapıyı doğrulamışıı. Bu alt faktörler; "örgütsel hafıza", "bilgi paylaşımı", "bilgi edinimi/kavrama" ve "bilgi duyarlılı̆ı" olarak adlandııımıştır. Orijinal ölçekte olduğu gibi uyarlama sonucunda da BYE-Ö'ünde 16 madde mevcuttur. Uyarlanan ölçeğin Türkiye Kültürü için geçerli ve güvenilir bir ölçme aracı olduğu tespit edilmiştir. Özellikle, bu ölçek, okullardaki bilgi yönetimi hakkında yönetimsel ve örgütsel çıkarımlarda bulunabilme noktasında faydalı olabilir.

Anahtar Kelimeler: bilgi yönetimi, okul yönetimi, bilgi, yönetim, öğretmen, okul

\section{Abstract}

The aim of this study is to adapt the "Knowledge Management Orientation Scale", which was developed by Wang, Ahmed \& Rafiq (2008), into Turkish culture. First, the linguistic equivalence of the Turkish version of the scale was achieved by consensus of a group of English experts. Later, data were collected from 206 volunteer teachers at the end of the 2017-2018 semester. Confirmatory Factor Analysis (CFA) was used to test the construct validity. The factor structure was determined to be acceptable and Turkish version of the scale consisted of four sub-scales as in the English version. The results of the CFA showed that model fit indices of the scale proved mostly a very good fit and good fit. It has been determined that BYE-Ö items can distinguish individuals well. The relationships between the overall of the scale and the scale factors were determined through the Pearson Correlation Coefficient. The values proved that there were statistically significant and positive relationships between scale overall and factors. It proves that the scale has internal consistency. Reliability of the scale was determined through Cronbach's Alpha Coefficient which was found to be .901 for the scale overall. It was .845 for the first factor; .712 for the second factor; .668 for third factor and .792 for the fourth factor. In conclusion, the adapted scale is a valid, reliable and measurement tool for Turkish culture. In particular, this scale may be useful for administrative and organizational inferences about knowledge management in schools.

Keywords: knowledge management, school management, knowledge, management, teacher, school

1 Zonguldak Bülent Ecevit Üniversitesi, Zonguldak, Türkiye, https://orcid.org/0000-0002-1318-9362

2 Milli Eğitim Bakanlığı, Türkiye, https://orcid.org/0000-0002-5830-7561

Atıf / Citation: Durnalı, M. ve Limon, İ. (2020). Bilgi Yönetimi Eğilimi Ölçeğinin Türkiye Kültürüne Uyarlanması: Geçerlik ve Güvenirlik Çalışması. Kastamonu Education Journal, 28(1), 95-106. doi:10.24106/kefdergi.3441 


\section{Abstract}

Introduction: It is important to make the lower and upper education systems (universities, parents, non-governmental organizations, associations, etc.) outside the school systems participate in school systems effectively while managing the resources in order to realize the aims of the organizations dealing with education and training activities. In this process, implementing adequate and necessary policies, practices, measures, and strategies for obtaining, sharing, using and storing the appropriate information efficiently and effectively can be called knowledge management (Durnalı, 2018). Knowledge management is the setting of standards to determine the value of information produced by employees in the organization and is a very strategic task (Nonaka, 1999). Knowledge management is the process of creating, storing and using the information to improve organizational performance (Bassi, 1997), often used to describe the processes of locating, organizing, transferring and using information (Duffy, 2000). Knowledge management is the capacity of the organization of information workers (groups, projects or other people working in other communities) to create, capture, share and disseminate collective information (Balasubramanian, Nochur, Henderson and Kwan, 1999). On the other hand, Wang, Ahmed \& Rafiq (2008) described the issue of knowledge management orientation based on the information provided by the researchers Szulanski (1996); Davenport, Delong \& Beers (1998); Holtshouse (1998); Popper \& Lipshitz (1998); Hansen, Nohria \& Tierney (1999); Alavi \& Leidner (2001); Gray (2001) and Hult (2003). They described as

"The degree to which a firm demonstrates behaviors of organized and systematic KM implementation in terms of building on its existing knowledge (organizational memory) as well as sharing tacit knowledge (knowledge sharing), assimilating external knowledge within the existing, internal knowledge frame (knowledge absorption), and being receptive to new knowledge (knowledge receptivity)."

Wang, Ahmed \& Rafiq (2008)'s main themes in knowledge management orientation framework can be explained as follows.

Organizational memory: It is about the system to capture, code, classify and store ideas and information in the organization and the information technologies that will facilitate these processes and to update the information systems continuously and update the stored information.

Knowledge sharing: It is about the existence of systems and spaces that provide information sharing and peer learning in the organization; knowledge and information sharing between superiors and subordinates, and frequent exchange of ideas based on interests among colleagues.

Knowledge absorption: It is about the use of information technologies for access to information not in the organization; knowledge and information sharing to generate new ideas to develop the organization, and the presence of networks where regular information sharing with other organizations can be realized.

Knowledge receptivity: It is about the shyness of putting forward the idea due to the fact that the new idea in the organization is heavily criticized or ignored; the benefit that will be provided to the organization, not the idea of who puts up an idea; the systematic evaluation of new ideas in a timely manner; the existence of a general culture where employees respect the right of knowledge and opinion and the inclusion of an employee who contributes to the idea to the process of developing and implementing this idea.

Method: The aim of this study is to adapt the 'Knowledge Management Orientation Scale', which developed by Wang, Ahmed \& Rafiq (2008), into Turkish culture. Firstly, the permission was granted by Dr. Wang for the adaptation of the scale. Later, the linguistic equivalence of the Turkish version of the scale was achieved by consensus of a group of English and Turkish experts. Later, data were collected from 206 volunteer teachers at the end of the 2017-2018 semester. The data used for the Confirmatory Factor Analysis (CFA) so that the construct validity of the scale could be tested. Factor load values, item coefficients, item statistics and model fit indices were calculated through CFA. In order to determine the reliability of the scale, Cronbach $\alpha$ coefficients were calculated separately for the scale overall and four sub-dimensions. Correlation coefficients for the relationship between factors; the relationship between sub-upper $27 \%$ groups was calculated to determine the item total correlations and item discrimination for internal consistency. The above analyzes were performed with Lisrel 8.1 program and SPSS.

Results and Conclusion: According to the results of the CFA, the factor structure was determined to be the acceptable and Turkish version of the scale consisted of four sub-scales as in the English version. That is to say, no item was excluded in the Turkish version of the scale in which there are 16 items while there are 16 items in the English version. Reliability of the scale was determined through Cronbach's Alpha Coefficient which was found to be .901 for the scale overall. It was .845 for the first factor; .712 for the second factor; .668 for third factor and .792 for the fourth factor. The results of the CFA showed that model fit indices of the scale proved mostly a very good fit and good fit (Chi Square=1.661; RMSEA =.058; $A G F I=.87 ; C F I=.98 ; G F I=.91 ; N N F I=$ .98; $N F I=.96 ; I F I=.98 ; R M R=.057 ; S R M R=.05)$. In addition, the relationships between the scale overall and the scale factors were determined through the Pearson Correlation Coefficient. The values proved that there are statistically significant and positive relationships between scale overall and factors. It proves that the subscales have a consistency. As a final point, it can be said that the adapted scale is a valid, reliable and measurement tool for Turkish culture. In particular, this scale may be useful for administrative and organizational inferences about knowledge management in schools.

Adapted Knowledge Management Orientation Scale has four factor which are "organizational memory" consisting of four items, "knowledge sharing" consisting of four items, "knowledge absorption" consisting of three items and "knowledge receptivity" consisting of five items, 16 items in total. It is in the form of Likert 5 type and degree of agreement varies between "Strongly Disagree" and "Strongly Agree". The 12th item is an item that is scored reverse. 


\section{Giriş}

Eğitim ve öğretim faaliyetleri ile uğraşan örgütlerin amaçlarını gerçekleştirmek için, kaynaklarının yönetiminde, okul sisteminin dışındaki alt ve üst sistemlerin (üniversiteler, veliler, sivil toplum örgütleri, dernek vb.) okuldaki eğitim öğretim sürecine etkili bir biçimde katılması önemlidir. Bu katılma sürecinde uygun bilginin elde edilmesi, paylaşıması, kullanılması ve depolanmasının verimli ve etkili bir şekilde işe koşulabilmesi noktasında yeterli ve gerekli politika, uygulama, tedbir ve stratejilerin bütününe bilgi yönetimi denilebilir (Durnalı, 2018). Bilgi yönetimi, örgütteki iş görenlerin ürettiği bilginin değerini tespit etmek için standartları belirlemektir ve oldukça stratejik bir görevdir (Nonaka, 1999). Bilgi yönetimi, örgütsel performansı artırmak için bilgi oluşturma, saklama ve kullanma sürecidir (Bassi, 1997), sıklıkla bilgilerin yerini belirleme, organize etme, aktarma ve kullanma süreçlerini tanımlamak için kullanııı (Duffy, 2000). Bilgi yönetimi, edinimi artırmak amacıyla örgütteki bilgi çalışanlarının (Gruplarda, projelerde veya diğer ilgili topluluklarda çalışan kişilerin) kolektif bilgiyi yaratması, yakalaması, paylaşması ve yaymalarını mümkün kılan örgüt kapasitesidir (Balasubramanian, Nochur, Henderson ve Kwan, 1999).

Bilgi yönetimi, büyük örgütsel hedefler ışığında, bireyler ve gruplar tarafından bilginin edinilmesi, oluşturulması, depolanması, paylaşılması, yayılması, geliştirilmesi ve uygulanması gibi örgüt çapında faaliyetlerin koordine edilmesi için gerekli sistematik ve bütünleşmiş bir süreç olarak tanımlanabilir (Rastogi, 2000). İş görenlerin edinimini ve örgütsel rekabet gücünü artırma amacıyla örgüt faaliyetleri için gerekli bilgileri seçme, süzme, depolama, organize etme, paketleme ve iletme noktasında istendik, sistematik, örgütsel ve en uygun biçime getirme stratejisine bilgi yönetimi denir (Bergeron, 2003). Bilgi yönetimi, genel olarak insan kaynakları, altyapı, teknoloji, bilgi ve bilgi çalışanları arasındaki karmaşık unsurlar, süreçler ve ilişkiler sistemidir. Bu ilişkiler, bilgi yönetiminin faaliyetini teşvik edebilecek veya engelleyebilecek bir 'iklim' içerisinde gerçekleşir (Khakpour, 2015).

Pek çok örgütsel öğrenme çıktı ve sonuçlarının; insan, teknoloji ve bilgi girdisi ve bu üçünü birbirine bağlayan teknolojik altyapı kaynaklarına dayandırılması bilgi yönetiminin temel iddiasıdır (Becerra-Fernandez ve Stevenson, 2001). Çapar (2003)'a göre bilgi yönetiminin amaçları arasında;

Örgütte yeni bilgi üretmek,

Örgüt dışındaki önemli bilgiyi örgüte kazandırmak,

Örgütsel karar alma sürecinde bilgiyi kullanılabilir yapmak,

Bilgiyi belge, veri tabanları ve bilgisayar programları aracılığıyla sunmak,

Örgütün içerisinde bulunduğu toplumun kültür vb. dinamiklerinden faydalanarak bilginin artmasını sağlamak,

Örgüt içi birimler arası bilgi paylaşımını gerçekleştirmek,

Örgütsel bilgiyi entelektüel sermayeye dönüştürmek amacıyla önemli biçime dönüştürmek ve ölçmek.

Günümüzde; yeni bilgiler sürekli bir biçimde üretilmektedir. Bilgi yayımını sağlayan gereçler sistemli ve sürekli bir biçimde yeni formlara dönüşmektedir. Bu durum bilgi tüketimini daha da artırabilmektedir. Bilimsel ve sanatsal araştırma, icat, keşif ve eserler yeni bilgiler ortaya çıkarmakta ve saklamaktadır. Bu bilgiler, gerek bireysel gerekse örgütsel faaliyetlerde, yenilikçi teknolojik araçlar olarak somutlaşabilmektedir (Akbaşlı \& Durnalı, 2017). Bilginin önemine vurgu yapan bu açıklamanın yanında bilgi yönetiminin önemi de şu açıklamalarda saklıdır. Bilgi yönetimi, örgüt varlıklarını daha da değerli yapma noktasında önemlidir (Yeniçeri, 2002). Bilgi yönetimi, hem açık hem de örtük bilginin birikimi, eğitim çıktılarını ve örgütsel etkinliği artıracak veriye dayalı karar verme sürecine (Santo, 2005) ve bilginin örgütte kimde ve nerede olduğu, kimlerce kullanıldığı, bu bilgiyle nelerin yapılabileceği ve bilgiyi kullanmak için gerekli davranış temelli engellerin kaldırılması noktasında katkıda bulunabilir (Erkollar, 2010).

Eğitim örgütlerinde, hem örgüt iklimi, kültürü ve fiziksel şartları hem de bu örgütlerde bilgiyi kullanacak iş görenlerin becerileri; bilginin etkin kullanımı, yeni bilginin sürekli olarak örgütsel ve bireysel davranışlara yansıması noktasında önemlidir (Özgözgü, 2015). Bilgi yönetiminin gelişmesi - dolayısıyla örgüt verimliliğinin artması - için örgüt içerisindeki iletişim biçiminin insan odaklı olması gerekmektedir. Örgütsel öğrenme, örgütsel bilgi yönetimi sürecinin devamlılı̆ını artıran bir unsurdur (Sağsan, 2002). Ayrıca, hem örgütsel hem de bireysel yaşantıda gerekli ve gereksiz bilgi önemli bir gerçek olarak durmaktadır. Bu bağlamda, okul bilgi yönetimi uğraşısında rol alan iş görenlerin örgütteki bilgi kirliliğine ilişkin sorunlara çözüm üretme noktasında gerekli önlemleri alabilme becerilerine sahip olması önemlidir (Durnalı, 2018). 
Öte taraftan, Wang, Ahmed ve Rafiq, (2008), bilgi yönetimi eğilimi konusunu, Szulanski (1996); Davenport, Delong \& Beers (1998); Holtshouse (1998); Popper \& Lipshitz (1998); Hansen, Nohria \& Tierney (1999); Alavi \& Leidner (2001); Grey (2001) ve Hult (2003) araştırmacılarının ortaya koyduğu bilgilerden faydalanarak şu şekilde tanımlamışlardır. Bir örgütün örgütlü ve sistematik bilgi yönetimi uygulamasını mevcut bilgi (örgütsel hafıza), örtük bilginin paylaşılması (bilgi paylaşımı), mevcut içsel bilgiyi dışsal bilgi ile özümseme (bilgi edinimi/kavrama) ve yeni bilgiye açık olma (bilgi duyarlılı̆ı) üzerine inşa etme noktasında örgütün davranışlarını gösterme derecesi olarak tanımlamışlardır. Wang, Ahmed ve Rafiq (2008)'ın bu çerçevesindeki alt faktörler şu şekilde açıklanabilir.

Örgütsel hafıza: Örgütte fikir ve bilgileri yakalayacak, kodlayacak, sınıflandıracak ve depolayacak sistemlerin ve bu süreçleri kolaylaştıracak bilgi teknolojilerinin varlığı ve bilgi sistemlerinin sürekli olarak elden geçirilip depolanan bilginin güncellenmesini kapsar.

Bilgi paylaşımı: Örgütte bilgi paylaşımı ve meslektaş öğrenimini sağlayan sistemler ve mekânların varlığı, üstler ve astlar arasında bilgi ve enformasyon paylaşımı ve meslektaşlar arasında çıkar temelli sık sık fikir alışverişini kapsar.

Bilgi edinimi/kavrama: Örgüt dışı bilgi ve enformasyona erişim için bilgi teknolojilerini kullanma, örgütü geliştirecek yeni fikirler üretmek için bilgi ve enformasyon paylaşımı ve diğer örgütler ile düzenli bilgi paylaşımının gerçekleştirilebildiği ağların mevcudiyetini kapsar.

Bilgi duyarlıığı: Örgütte yeni fikirlerin ağır şekilde eleştirildiği veya göz ardı edildiği için fikrin ortaya atılmasında çekingenliği, bir fikri kimin ortaya attığını değil örgüte sağlayacağı faydayı, yeni fikirlerin sistemli olarak zamanında değerlendirilmesini, çalışanların bilgi ve fikir hakkına saygı duydukları genel bir kültürün varlı̆̆ını ve yeni bir fikre katkıda bulunan bir çalışanın bu fikrin geliştirilmesi ve uygulanması sürecine dâhil edilmesini kapsar.

Çeşitli ulusal ve uluslararası üst politika belgelerinde; bilginin hızla üretildiği, değiştiği ve yayıldığı günümüzün bilgi çağının da bir gerekliliği olarak, Türkiye toplumunun bilgi toplumuna dönüşmesi noktasında bilgiler yer almaktadır. Eğitim örgütleri, bu bilgi yoğun sürecin gerektirdiği değişimlere ayak uydurma uğraşısında olmak durumundadır. Organisation for Economic Cooperation and Development [OECD] (2012)'e göre; bugün ihtiyaç duyulan öğretim, öğretmenlerin mesleki bilgilerinin yanı sıra kendi kişisel bilgilerini sürekli geliştiren üst düzey bilgi iş̧̧ileri olmasını gerektirir. Bu bağlamda; öğretmenlerin bilgi yönetimi eğilimlerine yönelik görüşlerini belirlemek oldukça önemli durmaktadır. Bu uyarlama çalışması, "Bilgi Yönetimi Eğilim Ölçeği” ile eğitim örgütünün bilgi yönetim süreçlerinde en aktif temel çalışanlardan olan öğretmenlerin örgütsel hafıza, bilgi paylaşımı, bilgi edinimi ve bilgi duyarlılığı temelinde bilgi yönetimi eğilimlerine yönelik görüşlerini ölçme uğraşındadır. Ayrıca, bu çalışma hem bilgi yönetimi alanında çalışan araştırmacılar hem de öğretmenlerde bir farkındalık oluşturarak; eğitim örgütlerinin bilgi yönetimi potansiyeline katkı sunma noktasında önemlidir. Türkiye Kültürü’ne uyarlanarak geçerlilik ve güvenilirliği kanıtlanmış olan bu ölçek, bilgi yönetimi eğilimi konusunu çözümleme temelinde alan yazındaki boşluğu gidermeye katkı sağlayacaktır.

Bu çalışmada, Türkiye Eğitim Sisteminde yer alan okulların bilgi yönetimi eğilimi düzeylerinin bilgi yönetimi eğilimi bütünü, örgütsel hafıza, bilgi paylaşımı, bilgi edinimi/kavrama ve bilgi duyarlılı̆̆ bağlamında öğretmenlerin görüşlerine göre çözümlenmesi amacıyla öğretmenlerce anlaşılması kolay ve araştırmacılar için pratik, kullanışı, kısa ve ücretsiz bir ölçme aracının uyarlamasını gerçekleştirmek amaçlanmıştır. Bu ölçme aracı, Wang, Ahmed ve Rafiq (2008) tarafından geliştirilen Bilgi Yönetimi Eğilimi Ölçeği (Knowledge Management Orientation Scale) (BYE-Ö)'dir.

\section{Yöntem}

Bu bölümde, çalışma grubu demografik bilgilerine ve ölçek uyarlama sürecine yer verilecektir.

\section{Çalışma Grubu}

BYE-Ö’nün Türkçe formları Doğrulayıcı Faktör Analizi (DFA) kapsamında gönüllük esasına dayalı olarak toplamda 206 öğretmene uygulanmıştır. Bu çalışma grubu toplam öğretmen sayısının uygunluğunu Bryman ve Cramer (1999; Tavşancıl, 2002)'ın şu açıklaması desteklemektedir: 100 katılımcıdan az olmamak üzere, faktör analizi uygulanacak katılımcı sayısı, ölçekteki toplam madde sayısının en az beş katı büyüklükte olmalıdır. Çalışma grubunu oluşturan öğretmenlerin demografik bilgileri Tablo 1'de sunulmuştur. Tablo 1'e göre, cinsiyete göre, DFA çalışma grubunun \% $45,1^{\prime}$ ini kadın öğretmenler ( $\left.f=93\right), \% 54,9^{\prime}$ unu ise erkek öğretmenler ( $f=113$ ) oluşturmuştur. Okul türüne göre, öğretmenlerin $\% 40,8^{\prime} i(f=84)$ lisede görev yapmaktadır. Deneyim açısından $16-20$ yıl grubu $(f=28), \% 13,6$ oranı ile en küçük paya sahiptir. Eğitim durumu değişkeni açısından ise çalışma grubunu oluşturan öğretmenlerin lisansüstü eğitim 
(yüksek lisans ( $f=91) \% 44,2^{\prime}$ si ve doktora $(f=28) \% 14,1^{\prime} i$ ) grubundakilerin toplam sayısı $(f=120) \% 58,3$ oranı ile lisans $(\mathrm{f}=86) \% 41,7$ grubundakilerden fazladır. Yaş açısından, 31-40 yaş grubu ( $\mathrm{f}=114), \% 44,2$ oranı ile en büyük orana sahiptir.

Tablo 1. Özgün ölçeğin Cronbach Alpha güvenirlik katsayıları

\begin{tabular}{llll}
\hline Değişken & & $\mathbf{f}$ & $\mathbf{\%}$ \\
\hline \multirow{2}{*}{ Cinsiyet } & Kadın & 93 & 45.1 \\
& Erkek & 113 & 54.9 \\
& Okul Öncesi & 10 & 4.9 \\
Okul Türü & illkokul & 36 & 17.5 \\
& Ortaokul & 76 & 36.9 \\
& Lise & 84 & 40.8 \\
& $0-5$ yıl & 32 & 15.5 \\
Deneyim & $6-10$ yıl & 45 & 21.8 \\
& $11-15$ yıl & 63 & 30.6 \\
& $16-20$ yıl & 28 & 13.6 \\
Eğitim Durumu & 21 yıl ve üzeri & 38 & 18.4 \\
& Lisans & 86 & 41.7 \\
& Yüksek Lisans & 91 & 44.2 \\
Yaş & Doktora & 29 & 14.1 \\
& $21-30$ yaş & 29 & 25.3 \\
& $31-40$ yaş & 114 & 44.2 \\
& $41-50$ yaş & 44 & 23.8 \\
& 51 ve üzeri yaş & 19 & 6.8 \\
\hline
\end{tabular}

Çalışma grubu toplam sayı: 206

\section{Ölçme Aracı}

Bu çalışmada Türkiye Kültürüne uyarlaması gerçekleştirilen ölçek; Wang, Ahmed ve Rafiq (2008) tarafından geliştirilen Bilgi Yönetimi Eğilimi Ölçeği (Knowledge Management Orientation Scale) (BYE-Ö)'dir. Orijinal ölçek, dört maddeden oluşan "örgütsel hafıza" (Organizational memory), dört maddeden oluşan "bilgi paylaşımı" (Knowledge sharing), üç maddeden oluşan "bilgi edinimi/kavrama"(Knowledge absorption) ve beş maddeden oluşan "bilgi duyarlılı̆ı̆" (Knowledge receptivity) toplamda dört faktör ve 16 maddeden oluşmaktadır. Ölçeğin özgün dili İngilizce'dir.

Ölçek, “Kesinlikle Katılmıyorum (1)”, ..., “Kesinlikle Katılıyorum (7)” olmak üzere 7’li Likert tipindedir. Ancak, 7’li Likert tipinin Türkçe karşılığında anlam ve anlaşılırlık noktasında seçenekler birbirine çok yakın olduğu için karışıklık oluşabilir (Şeker ve Gençdoğan, 2006; Akt. Doğan ve Akıncı Çötok, 2011). Bu sebeple, Türkçe form 5’li Likert tipinde düşünülmüştür. Yani, ölçeğin Türkçe formundaki seçenekler "Kesinlikle Katılmıyorum", "Katılmıyorum", "Kararsızım", "Katılıyorum" ve "Tamamen Katılıyorum" şeklindedir. 12. madde ters puanlanan bir maddedir. Orijinal çalışmada ölçeğin güvenirlik katsayıları ise Tablo 2'de belirtildiği gibi şu şekildedir. Örgütsel hafıza faktörü için 0.86; bilgi paylaşımı faktörü için 0.85; bilgi edinimi/kavrama faktörü için 0.78; bilgi duyarlılığı faktörü için 0.84 ve Ölçek Bütünü için 0.92 'dir.

Tablo 2. Özgün ölçeğin Cronbach's Alpha güvenirlik katsayıları

\begin{tabular}{|c|c|c|}
\hline \multicolumn{2}{|c|}{ Özgün Ölçek } & \multirow{2}{*}{$\begin{array}{c}\text { Cronbach Alpha Katsayısı } \\
0.86\end{array}$} \\
\hline \multirow{4}{*}{ 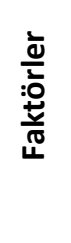 } & Örgütsel hafıza (organizational memory) & \\
\hline & Bilgi paylaşımı (knowledge sharing) & 0.85 \\
\hline & Bilgi edinimi/kavrama (knowledge absorption) & 0.78 \\
\hline & Bilgi duyarlılı̆ıı (knowledge receptivity) & 0.84 \\
\hline \multicolumn{2}{|c|}{ Ölçek Bütünü } & 0.92 \\
\hline
\end{tabular}




\section{Uyarlama Süreci}

Öncelikle, BYE-Ö’nün Türkiye Kültürüne uyarlanması için ölçeği geliştiren sorumlu araştırmacılardan e-posta aracılığıyla izin alınmıştır. BYE-Ö’nün içeriği bağlamında İngilizce ve Türkçe dillerinde üç uzman, ölçek maddelerini İngilizce'den Türkçe'ye fikir birliğiyle çevirmiştir. Dil geçerliliği sağlandıktan sonra, Doğrulayıcı Faktör Analizi (DFA) ile ölçeğin Türkiye Kültürüne uyumu, yapı geçerliliği açısından test edilmiştir. DFA sonuçları Açımlayı Faktör Analizine (AFA) gerek olmadığını işaret ettiği için AFA'ya gerek duyulmamıştır.

\section{Verilerin Analizi}

Çalışma grubunun demografik özelliklerini çözümlemek için frekans ve yüzde hesaplamaları gerçekleştirilmiştir. Türkiye Kültürüne uyarlanan ölçeğin yapı geçerliliğini test etmek için 206 öğretmenin görüşlerinden oluşan veri seti üzerinde DFA gerçekleştirilmiştir. DFA'da faktör yük değerleri, maddeler ve boyutlar arasındaki yol katsayıları, madde istatistikleri, uyum iyiliği değerleri hesaplanmıştır. Ölçeğin güvenirliğini tespit etmek için ölçek bütününün ve dört alt boyutun her biri için ayrı olarak Cronbach's Alfa $(\alpha)$ katsayıları hesaplanmıştır. Faktörler arası ilişki için korelasyon katsayıları; iç tutarlılı̆ı için madde toplam korelasyonları ve madde ayırt ediciliklerini tespit etmek için Alt-Üst \% 27’lik gruplar arasındaki ilişki hesaplanmıştır. Yukarıdaki analizler, Lisrel 8.1 ve SPSS programı ile gerçekleştirilmiştir.

\section{Bulgular}

Bu bölümde, Türkiye Kültürüne uyarlaması gerçekleştirilen Bilgi Yönetimi Eğilimi Ölçeğinin, uyarlama sürecinde gerçekleştirilen çalışmalar/analizler sonucunda ulaşılan bulgular ve yorumlara yer verilmiştir. Sırasıyla, dil geçerliliği, yapı geçerliliği ve güvenirliliğine ilişkin bulgular aktarılacaktır.

\section{Dil Geçerliliğine ilişkin Bulgular}

BYE-Ö’nün içeriği bağlamında İngilizce ve Türkçe dillerinde üç uzman, ölçek maddelerini İngilizce'den Türkçe'ye fikir birliğiyle çevirmiştir. Tartışma sonucunda, çevirisi gerçekleştirilen ölçek ile özgün ölçek arasında dil geçerliliği açısından sorun oluşturabilecek bir fark oluşmadığı tespit edilmiştir. Bu süreç sonucunda ölçeğin dil geçerliliğinin kabul edilebilir olduğu düşünülmüştür.

\section{Doğrulayıcı Faktör Analizi (DFA) ilişkin Bulgular}

Ölçeğin yapı geçerliğini test etmek amacıyla öğretmenlerden toplanan veri seti üzerinde DFA yürütülmüştür. Şekil 1'de DFA sonucunda elde edilen yol diyagramı üzerinde, faktörlere, maddelerin faktör yük - hata varyans gibi değerlerine ve madde modifikasyonu işlemine yer verilmiştir.

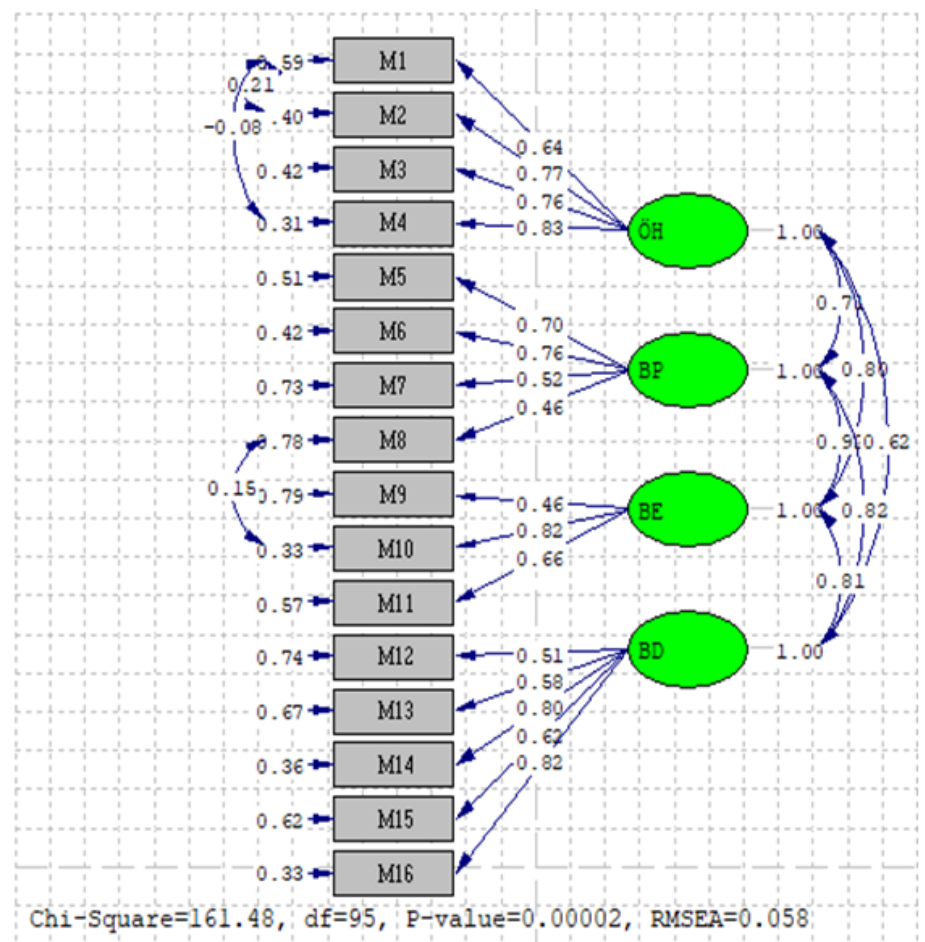

Şekil 1. Bilgi Yönetimi Eğilimi Ölçeği Yol Diyagramı 
Şekil 1, DFA sonucunda faktör yük değerlerinin .46 ile .83 arasında, hata varyans değerlerinin ise .31 ile .79 arasında olduğunu göstermektedir. Ve bu değerler anlamlı bir düzeydedir. Şekil 1, örgütsel hafıza faktörünü oluşturan maddelerin faktör yük değerlerinin .64-.83; bilgi paylaşımı faktörünü oluşturan maddelerin faktör yük değerlerinin .46.76; bilgi edinimi/kavrama faktörünü oluşturan maddelerin faktör yük değerlerinin .46-.82 ve bilgi duyarlılığı faktörünü oluşturan maddelerin faktör yük değerlerinin ise .51-.82 değerleri arasında olduğunu göstermektedir. Stevens (2002)'e göre, faktör yük değerinin mutlaka 0.40'ın üstünde olması gerekmektedir. Büyüköztürk (2016)'e göre ise faktör yükleri için .30 minimum alt kesme noktası olarak alınabilir. Bu durumda, DFA sonucunda elde edilen faktör yük değerlerinin kabul edilebilir düzeyde olduğu ifade edilebilir. Türkiye Kültürüne uyarlaması gerçekleştirilen BYE-Ö, DFA sonuçları ile doğrulanan model, boyut ve madde ilişkisi ve sayısı açısından özgün ölçek ile birebir örtüşen bir modeldir.

Tablo 3. Bilgi Yönetimi Eğilimi Ölçeği DFA bulgularına ilişkin madde istatistikleri

\begin{tabular}{clllll}
\hline Faktörler & Madde & $\boldsymbol{\lambda}$ & $\mathbf{R}^{\mathbf{2}}$ & Hata Varyansı & $\mathbf{t}$ \\
\hline \multirow{3}{*}{ Örgütsel hafıza } & 1 & .64 & .41 & .59 & $8.99^{* *}$ \\
& 2 & .77 & .60 & .40 & $12.30^{* *}$ \\
& 3 & .76 & .58 & .42 & $12.06^{* *}$ \\
Bilgi paylaşımı & 4 & .83 & .69 & .56 & $13.51^{* *}$ \\
& 5 & .70 & .49 & .51 & $10.73^{* *}$ \\
Bilgi & 6 & .76 & .58 & .42 & $11.88^{* *}$ \\
edinimi/kavrama & 7 & .52 & .27 & .73 & $7.40^{* *}$ \\
& 8 & .46 & .22 & .78 & $6.49^{* *}$ \\
Bilgi duyarlılığı & 9 & .46 & .21 & .79 & $6.54^{* *}$ \\
& 10 & .82 & .67 & .33 & $13.14^{* *}$ \\
& 11 & .66 & .43 & .57 & $9.94^{* *}$ \\
& 12 & .51 & .26 & .74 & $7.33^{* *}$ \\
& 13 & .58 & .33 & .67 & $8.51^{* *}$ \\
& 14 & .80 & .64 & .46 & $13.03^{* *}$ \\
& 15 & .62 & .38 & .62 & $9.21^{* *}$ \\
& 16 & .82 & .67 & .33 & $13.41^{* *}$ \\
\hline
\end{tabular}

${ }^{* *} p<, 01$

Kline (2011)'a göre, t-değeri 1.96'dan büyük ise .05 düzeyinde, 2.58'in üzerinde ise .01 düzeyinde anlamlılık söz konusudur. Bu temelde, Tablo 3'e göre, t-değerlerinin tamamının .01 düzeyinde anlamlı olduğu ifade edilebilir.

Tablo 4. Bilgi Yönetimi Eğilimi Ölçeği Uyum İyiliği Değerleri

\begin{tabular}{llllllllllll}
\hline \multicolumn{2}{l}{ Uyum Indeksleri } & & & & & & & & & & \\
\hline Modifikasyon & $\mathbf{x}^{2} / \mathbf{d f}$ & $\mathbf{p}$ & RMSEA & CFI & GFI & AGFI & NNFI & NFI & IFI & RMR & SRMR \\
Öncesi & 2.085 & .000 & .075 & .970 & .890 & .840 & .960 & .940 & .970 & .061 & .054 \\
SonrasI & 1.661 & .000 & .058 & .980 & .910 & .870 & .980 & .960 & .980 & .057 & .050 \\
\hline
\end{tabular}

Tablo 4'te Bilgi Yönetimi Eğilimi Ölçeğinin uyum iyiliği değerlerine yer verilmiştir. Modifikasyon öncesi, Hu ve Bentler (1999) ile Marcoulides ve Schumacher (2001)'in normal kabul ettiği değerler temel alındığında; x2/df, RMSEA, RMR ve SRMR ölçüt değerlerin üzerinde ve GFI, AGFI ve NFI değerleri ise normal kabul edilen değerlere yakın çıkmıştır. Analiz sonucunda istenen değerlerin yakalanabilmesi amacıyla programın modifikasyon önerileri dikkate alınmış ve şu maddeler arasında modifikasyona gidilmiştir. Madde 1 ile madde 4, madde 1 ile madde 2 ve madde 8 ile madde 10 aralarında modifikasyon işlemi gerçekleştirilmiştir. Bu işlem sonucunda istenen değerlere ulaşılmıştır. Modifikasyon sonrası elde edilen uyum iyiliği değerleri Tablo 5'de detaylı bir biçimde açıklanmıştır.

Tablo 5'deki, model uyum iyiliğinin belirlenmesi için normal değerler ve kabul edilebilir değerler Hu ve Bentler (1999) ile Marcoulides ve Schumacher (2001) araştırmacılarının ileri sürdüğü değerlerdir. Tablo 5'de, $\chi 2 / s d=1.661$ değerinin mükemmel uyum düzey aralığında olduğu tespit edilmiştir. RMSEA $=.058$ ve AGFI $=.87$ değerleri kabul edilebilir uyum düzeyinde çıkmıştır. $\mathrm{CFI}=.98, \mathrm{GFI}=.91, \mathrm{NNFI}=.98, \mathrm{NFI}=.96, \mathrm{IFI}=.98, \mathrm{RMR}=.057$ ve $\mathrm{SRMR}=.05$ değerleri mükemmel uyum düzeyinde çıkmıştır. RMSEA ve SRMR değerlerinin 0.08 ' den küçük çıkması model ile veri uyumunun üst düzeyde olduğunun bir işaretidir (Hu ve Bentler, 1999). DFA'dan elde edilen bu uyum iyiliği bulguları, ölçeğin faktör yapısının kabul edilebilir uyum gösterdiğinin işareti olarak yorumlanabilir. 
Tablo 5. Normal, Kabul Edilebilir ve BYE-Ö Uyum İyiliği Değerleri

\begin{tabular}{lllll}
\hline Uyum Indeksi & Normal Değer & Kabul Edilebilir Değer & BYE-Ö Elde Edilen Değer & Sonuç \\
\hline$x 2 / d f$ & $0-2$ & $2-3$ & 1.661 & Mükemmel uyum \\
RMSEA & $\leq .05$ & $\leq .08$ & 0.058 & Kabul edilebilir uyum \\
CFI & $\geq .95$ & $\geq 90$ & 0.98 & Mükemmel uyum \\
GFI & $\geq .90$ & $\geq .85$ & 0.91 & Mükemmel uyum \\
$\mathrm{AGFI}$ & $\geq .90$ & $\geq .85$ & 0.87 & Kabul edilebilir uyum \\
$\mathrm{NNFI}$ & $\geq .95$ & $\geq .90$ & 0.98 & Mükemmel uyum \\
$\mathrm{NFI}$ & $\geq .95$ & $\geq .90$ & 0.96 & Mükemmel uyum \\
$\mathrm{IFI}$ & $\geq .95$ & $\geq .90$ & 0.98 & Mükemmel uyum \\
$\mathrm{RMR}$ & $\leq .05$ & $\leq .08$ & 0.057 & Mükemmel uyum \\
SRMR & $<.05$ & $<.08$ & 0.05 & Mükemmel uyum \\
\hline
\end{tabular}

BYE-Ö bütününün ölçme kapasitesini ve ölçek maddelerinin ayırt ediciliğini tespit etmek için düzeltilmiş madde toplam korelasyonları ve Alt-Üst \% 27'lik gruplar arasındaki fark hesaplanmıştır. Ölçek maddelerinden elde edilen puanlar ile toplam puan arasındaki ilişkinin açıklandığı madde-toplam korelasyonunun pozitif ve yüksek olması, ilgili faktördeki maddelerin benzer durumları topladığını ve iç tutarlılı̆ın yüksek olduğuna işaret eder. Alt-üst \%27'lik gruplar arasında istendik yönde gözlenen farkların anlamlı çıkması ise ayırt ediciliğin bir göstergesi olarak kabul edilir (Büyüköztürk, 2011). Bu analiz sonucuna ilişkin bulgular Tablo 6'da yer verilmiştir.

Tablo 6. BYE-Ö Alt-Üst \% 27 Madde Analizi Bulguları

\begin{tabular}{llll}
\hline Faktörler & $\begin{array}{l}\text { Madde } \\
\text { No }\end{array}$ & Madde Toplam Korelasyonu ${ }^{\mathbf{1}}$ & t (Alt-Üst \% 27) \\
\hline \multirow{3}{*}{ Örgütsel hafıza } & 1 & .542 & $8.492^{*}$ \\
& 2 & .629 & $13.163^{*}$ \\
& 3 & .594 & $11.462^{*}$ \\
Bilgi paylaşımı & 4 & .607 & $11.383^{*}$ \\
& 5 & .642 & $14.305^{*}$ \\
& 6 & .672 & $11.429^{*}$ \\
Bilgi edinimi/kavrama & 7 & .447 & $7.197^{*}$ \\
& 8 & .414 & $5.794^{*}$ \\
& 9 & .418 & $6.163^{*}$ \\
Bilgi duyarlılığı & 10 & .753 & $15.579^{*}$ \\
& 11 & .595 & $11.165^{*}$ \\
& 12 & .396 & $7.376^{*}$ \\
& 13 & .554 & $9.991^{*}$ \\
& 14 & .670 & $12.031^{*}$ \\
\hline
\end{tabular}

\% 27 Alt - Üst " $t$ " testi analizi için, $N=206, \% 27$ için $n 1=n 2=56, s d=110,{ }^{*} p<, 001$

Tablo 6'da ölçeğin düzeltilmiş madde toplam korelasyon katsayılarına yer verilmiştir. Bu katsayılar .396 ile .753 arasında değişmektedir. Büyüköztürk (2011)'e göre; maddelerin bireyleri iyi derecede ayırt edebilmesi için madde toplam korelasyonu değerlerinin .30 veya üzerinde olması gerekmektedir. Bu temelde, BYE-Ö'ün maddelerinin bireyleri iyi derecede ayırt edebildiği ifade edilebilir. Bu temelde, BYE-Ö bütün maddelerinde Alt-Üst \% 27'lik gruplar arasında gözlenen fark anlamlı çıkmıştır. Yani, t-değerlerinin tamamının .01 düzeyinde anlamlı olduğu ifade edilebilir. Bu bulgular ışığında, BYE-Ö iç tutarlılığının ve maddelerin ayırt ediciliğinin uygun düzeyde olduğu ifade edilebilir.

Güvenirliliğe İlişkin Bulgular

Tablo 7. Bilgi Yönetimi Eğilimi Ölçeği Güvenirlik Analizi Katsayıları

\begin{tabular}{|c|c|c|c|}
\hline & BYE-Ö & Madde Sayısı & Cronbach Alpha Katsayısı \\
\hline \multirow{4}{*}{ 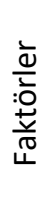 } & Örgütsel hafıza & 4 & .845 \\
\hline & Bilgi paylaşımı & 4 & .712 \\
\hline & Bilgi Edinimi/Kavrama & 3 & .668 \\
\hline & Bilgi duyarlılığı & 5 & .792 \\
\hline \multicolumn{2}{|c|}{ Ölçek Bütünü } & 16 & .901 \\
\hline
\end{tabular}


Tablo 7'de ölçeğin bütünü ve faktörlerine ilişkin güvenirlik katsayılarına yer verilmiştir. BYE-Ö'ün bütünü ve faktörlerinde Cronbach Alpha güvenirlik katsayısının uygun düzeylerde -Tezbaşaran (1997)'a göre ölçüt .70 alınmalıdır - olduğu ifade edilebilir. Cronbach Alpha güvenirlik katsayıları, örgütsel hafıza faktörü için .845; bilgi paylaşımı faktörü için .712; bilgi edinimi/kavrama faktörü için .668; bilgi duyarlılığı faktörü için .792 ve ölçek bütünü için .901'dir. Bu güvenirlik katsayılarının uygun ölçütleri karşıladığı ifade edilebilir.

Tablo 8. Bilgi Yönetimi Eğilimi Ölçeğinin Bütünü ve Faktörleri Arasındaki ílişki

\begin{tabular}{|c|c|c|c|c|c|c|}
\hline \multicolumn{2}{|c|}{ BYE-Ö } & 1 & 2 & 3 & 4 & 5 \\
\hline \multirow{4}{*}{ 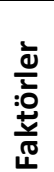 } & 1. Örgütsel hafıza & 1 & & & & \\
\hline & 2. Bilgi paylaşımı & $.512^{* *}$ & 1 & & & \\
\hline & 3. Bilgi edinimi/kavrama & $.578^{* *}$ & $.688^{* *}$ & 1 & & \\
\hline & 4. Bilgi duyarlılığı & $.510^{* *}$ & $.620^{* *}$ & $.612^{* *}$ & 1 & \\
\hline \multicolumn{2}{|c|}{ Ölçek Bütünü } & $.790^{* *}$ & $.836^{* *}$ & $.838^{* *}$ & $.851^{* *}$ & 1 \\
\hline
\end{tabular}

$* * p<, 01$

BYE-Ö’ün bütünü ve faktörleri aralarındaki ilişkiyi tespit etmek için Pearson Korelasyon katsayıları hesaplanmıştır. Tablo 8' de bu katsayılara yer verilmiştir. Korelasyon katsayısı 0.29 ' un altında ise düşük; 0.30 ile 0.69 arasında ise orta ve 0.70 ile 1.00 arasında ise yüksek düzeyde ilişki vardır denilebilir (Büyüköztürk, 2011). Bu bağlamda, örgütsel hafıza ile bilgi paylaşımı $(r=0.512)$, örgütsel hafıza ile bilgi edinimi/kavrama $(r=0.578)$, örgütsel hafıza ile bilgi duyarlılığı $(r=0.510)$, bilgi paylaşımı ile bilgi edinimi/kavrama $(r=0.688)$, bilgi paylaşımı ile bilgi duyarlılığı $(r=0.620)$ ve bilgi edinimi/kavrama ile bilgi duyarlılığı $(r=0.612)$ faktörleri arasında orta düzeyde ilişki vardır denilebilir. Örgütsel hafıza ile ölçek bütünü ( $r=0.790)$, bilgi paylaşımı ile ölçek bütünü $(r=0.836)$ ve bilgi edinimi/kavrama ile ölçek bütünü $(r=0.838)$ faktörleri arasında ise yüksek düzeyde bir ilişki vardır denilebilir. Ölçek bütünü ve alt faktörlerin ilişki katsayısı değerleri, ölçek bütünü ve alt faktörleri arasında pozitif yönlü anlamlı doğrusal bir ilişki olduğunu işaret etmektedir. Örneğin, bu durum, örgütsel hafıza düzeyinin yüksek olması durumunda bilgi duyarlılığı düzeyinin de yüksek olduğuna işaret etmektedir.

\section{Sonuçlar}

Bu çalışmada, Wang, Ahmed ve Rafiq (2008) tarafından geliştirilen Bilgi Yönetimi Eğilimi Ölçeği (Knowledge Management Orientation Scale) (BYE-Ö)'nün Türkiye Kültürüne uyarlaması kapsamında geçerlik ve güvenirlik çalışmaları gerçekleştirilmiştir. Uyarlama sonucunda, özgün ölçekte olduğu gibi BYE-Ö dört alt faktörden oluşmuştur. Bu alt faktörler, "örgütsel hafıza", "bilgi paylaşımı", "bilgi edinimi/kavrama” ve "bilgi duyarlılı̆ı" olarak adlandırılmıştır. Orijinal ölçekte olduğu gibi "örgütsel hafıza" dört, "bilgi paylaşımı" dört, "bilgi edinimi/kavrama" üç ve "bilgi duyarlılığı" beş madde ve BYE-Ö bütününde 16 madde mevcuttur. Türkçe form 5'li Likert tipinde, "Kesinlikle Katılmıyorum", "Katılmıyorum", "Kararsızım", "Katılıyorum" ve "Kesinlikle Katılıyorum" seçenekleri şeklindedir. 12. madde ters puanlanan bir maddedir.

Uyarlama sürecinde, ilk olarak BYE-Ö İngilizce Türkçe dil eşdeğerliği çalışması gerçekleştirilmiştir. Bu süreç sonucunda, uyarlanan BYE-Ö’nün Türkçe formundaki maddelerin özgün ölçekteki maddeler ile dil ve anlam açısından eşdeğer olduğu ortaya konulmuştur. Dil eşdeğerliği çalışması sonrasında, DFA gerçekleştirilmiştir. DFA sonucunda, elde edilen faktör yük ve hata varyans değerlerinin kabul edilebilir düzeyde olduğu tespit edilmiştir. Madde analizi sonucunda t-değerlerinin tamamının .01 düzeyinde anlamlı olduğu görülmüştür. DFA'dan elde edilen uyum iyiliği bulguları, ölçeğin faktör yapısının kabul edilebilir uyum gösterdiğini işaret etmiştir. İki uyum iyiliği indeksi "kabul edilebilir" düzeyde, yedi indeks ise "mükemmel uyum" düzeyinde çıkmıştır. Alt-Üst \% 27 madde analizi sonucuna göre; BYE-Ö’nün bütün maddelerinde Alt-Üst \% 27'lik gruplar arasındaki fark anlamlı bulunmuştur. Yani, t-değerlerinin tamamının 01 düzeyinde anlamlı çıkmıştır. Madde toplam korelasyon katsayı bulguları maddelerin bireyleri iyi derecede ayırt edebildiğine işaret etmiştir. Sonuçta, BYE-Ö iç tutarlılı̆ının ve maddelerin ayırt ediciliğinin uygun düzeyde olduğu tespit edilmiştir. DFA sonuçlarına göre; Türkiye Kültürüne uyarlaması gerçekleştirilen BYE-Ö’nün uyarlama sürecinde ortaya çıkan yeni model, boyut ve madde ilişkisi ve sayısı açısından özgün ölçek ile birebir örtüşen bir modeldir.

Cronbach's Alpha güvenirlik katsayıları, ölçeğin faktörleri ve ölçek bütünü için alan yazında belirtilen uygun ölçütleri karşılamıştır. Bu bulgular, BYE-Ö bütününün ve faktörlerinin güvenilir olduğunu işaret etmektedir. Özellikle, BYE-Ö bütünü .901 gibi yüksek düzeyde bir güvenirliğe sahiptir. BYE-Ö'ün bütünü ve faktörleri aralarında bazı durumlarda orta düzeyde ilişki ve bazılarında yüksek düzeyde bir ilişki mevcuttur. Bu bulgular, ölçek bütünü ve alt 
faktörleri arasında pozitif yönlü anlamlı doğrusal bir ilişki olduğunu işaret etmektedir. Yani, bir faktörün düzeyinin yüksek olması, diğer bir faktörün ve BYE-Ö bütünü düzeyinin de yüksek olacağı anlamına gelmektedir. Bu durumun tersi de geçerlidir.

Bu bulgular, Bilgi Yönetimi Eğilimi Ölçeğinin, okullarda bilgi yönetimi eğilimi konusunun çözümlenmesi noktasında geçerli ve güvenilir bir ölçme aracı olduğunu ortaya koymuştur. BYE-Ö, öğretmenlerce kolayca anlaşılabilir ve araştırmacılar için pratik, kullanışlı, kısa, erişime açık ve ücretsiz bir ölçektir.

\section{5. Öneriler}

Bu ölçeğin, okullarda bilgi yönetimi eğilimi düzeylerinin bilgi yönetimi eğilimi bütünü, örgütsel hafıza, bilgi paylaşımı, bilgi edinimi/kavrama ve bilgi duyarlılı̆̆ bağlamında öğretmenlerin görüşlerine göre tespit etmek amacıyla kullanılması önerilmektedir. Bu ölçek, okullardaki bilgi yönetimi hakkında yönetimsel ve örgütsel çıkarımlarda bulunabilme noktasında faydalı olabilir. Örneğin, bilgi yönetimi eğilimi düzeyleri düşük çıkan okullar, örgütlerinin amaç, yapı, işleyiş, işbirlikçi iklim, kültür, yenilikçilik, bilgi üretimi, okul yönetim süreçleri, ast üst ve yatay iletişim vb. konularda çeşitli çıkarımlar yaparak okul örgütünün yaşamını devam ettirebilmek ve verimi artırmak adına gerekli önlem ve tedbirleri sağlayabilirler. Yani, bu ölçek, okul örgütünün bilgi yönetimi potansiyelini ortaya çıkararak eğitim yönetimi uğraşılarına katkı sağlayabilecek özellikleri barındırmaktadır.

Son olarak, okullarda bilgi yönetimi eğilimi konusunu çözümlemek adına, bu ölçek maddeleri merkeze alınarak, nitel yöntem vb. desteklenerek yeni ölçme araç(lar)ı geliştirilebilir. Bu sayede, konunun detaylı biçimde çözümlenme uğraşısına katkı sağlanarak alan yazına da katkı sağlanabilir. Ayrıca, bu konunun çeşitli liderlik yaklaşımları (örn. teknolojik liderlik (Durnalı, 2018)), çeşitli örgütsel davranışlar, örgütsel amaç (Durnalı ve Koşar, 2019), işbirlikçi iklim (Limon ve Durnalı, 2017) vb. konular ile ilişkilerinin ortaya çıkarılabileceği çalışmalar gerçekleştirilebilir.

\section{Kaynakça}

Akbaşlı, S. ve Durnalı, M. (2017). Halk eğitim merkezlerinde çalışan iş görenlerin yaşam boyu öğrenme anahtar yeterlik algıları. OPUS-Ulus/ararası Toplum Araştırmaları Dergisi, 7(13), 726-741. doi: 10.26466/opus.342207

Balasubramanian, P., Nochur, K., Henderson, J. C., ve Kwan, M. M. (1999). Managing process knowledge for decision support. Decision Support Systems, 27(1-2), 145-162.

Bassi, L. J. (1997). Harnessing the power of intellectual capital. Training ve Development, 51(12), 25-31.

Becerra-Fernandez, I., ve Stevenson, J.M. (2001). Knowledge management systems ve solutions for the school principal as chief learning officer. Education, 121(3), 508-518.

Bergeron, B. (2003). Essentials of knowledge management. Hoboken: John Wiley ve Sons, Inc.

Bryman, A., ve Cramer, D. (1999). Quantitative data analysis with SPSS release 8 for Windows. London ve New York: Taylor and Francis.

Büyüköztürk, Ş. (2011). Sosyal Bilimler İçin Veri Analizi El Kitabı. Ankara: PEGEM Akademi Yayınları.

Büyüköztürk, Ş. (2016). Veri analizi el kitabı. Ankara: PEGEM Akademi Yayınları.

Çapar, B. (2003). Bilgi yönetimi: Nasıl bir insan gücü? II. Ulusal Bilgi, Ekonomi ve Yönetim Kongresi Bildiriler Kitabı (421432), Kocaeli Üniversitesi İktisadi ve İdari Bilimler Fakültesi, Kocaeli, 17-18 Mayıs 2003.

Doğan, T. ve Akıncı Çötok, N. (2011). Oxford Mutluluk Ölçeği Kısa Formunun Türkçe Uyarlaması: Geçerlik ve Güvenirlik Çalışması. Türk Psikolojik Danışma ve Rehberlik Dergisi, 4(36), 165-172.

Duffy, J. (2000). Knowledge management: What every information professional should know. Information Management, 34(3), 10.

Durnalı M. \& Koşar, D. (2019). Bir uzaktan eğitim uygulama ve araştırma merkezinin örgütsel amaçlarının analizi: Bir devlet üniversitesi örneği. Balıkesir Üniversitesi Sosyal Bilimler Enstitüsü Dergisi, 22(42), 85-110.

Durnalı, M. (2018). Okul müdürü teknolojik liderlik davranışı ve okul bilgi yönetimi düzeylerine ilişkin öğretmen görüşleri (Doktora Tezi). Hacettepe Üniversitesi, Eğitim Bilimleri Enstitüsü, Ankara.

Erkollar, A. (2010). İntranet ve Bilgi Yönetim Portalları. M. Dinçmen (Ed.), Bilgi yönetimi ve uygulamaları. (ss. 229-248). İstanbul: Papatya Yayıncılık. 
Hu, L. T., ve Bentler, P. M. (1999). Cutoff criteria for fit indexes in covariance structure analysis: Conventional criteria versus new alternatives. Structural Equation Modeling, 6(1), 1-55.

Khakpour, A. (2015). Knowledge management in educational organizations: Opportunities and challenges. In 7th International Knowledge Management Conference. Beheshti Intl. Conference Center, Tehran, Iran, Feb. 17-18, 2015.

Kline, R. B. (2011). Principles and practice of structural equation modeling (3nd ed.). New York London: The Guilford.

Limon, İ. ve Durnalı, M. (2017). İşbirlikçi iklim Ölçeğinin Türkçe'ye Uyarlanması: Geçerlik ve Güvenirlik Çalışması. Sakarya University Journal of Education, 7(2), 282-294.

Marcoulides, G., ve Schumacher, R. (2001). New developments and techniques in structural equation modelling. Londra: Lawrence Erbaum Associates Publishers.

Nonaka, I. (1999). Bilgi yaratan şirket, Harvard Business Review (Seçmeler) bilgi yönetimi. İstanbul: MESS Yayınları.

OECD (Organisation for Economic Cooperation and Development) (2012). Preparing teachers and developing school leaders for the 21st century: Lessons from around the world. Paris: OECD Publishing.

Özgözgü, S. (2015). Eğitim örgütlerinde yöneticilerin liderlik davranışları, bilgi yönetimi ve örgüt kültürü ilişkisi (Doktora Tezi). Ege Üniversitesi, Sosyal Bilimler Enstitüsü, İzmir.

Rastogi, P. N. (2000). Knowledge management and intellectual capital-the new virtuous reality of competitiveness. Human Systems Management, 19(1), 39-48.

Sağsan, M. (2002). Örgütsel seçimlerde küme modeli: İnsan ilişkileri, bilgi yönetimi ve örgütsel öğrenmenin ara kesitinde "insan". Bilgi Dünyası, 3(2), 205-230.

Santo, S. A. (2005). Knowledge management: An imperative for schools of education. TechTrends, 49(6), 42-49. DOI: 10.1007/BF02763729

Stevens, J. P. (2002). Applied multivariate statistics for the social sciences (4th ed.). Hillsdale, NS: Erlbaum.

Tavşancıl, E. (2002). Tutumların ölçülmesi ve SPSS ile veri analizi. Ankara: Nobel Akademi.

Türk, M. (2003). Küreselleşme sürecinde işletmelerde bilgi yönetimi. İstanbul: Türkmen Kitabevi.

Wang, C. L., Ahmed, P. K., ve Rafiq, M. (2008). Knowledge management orientation: Construct development and empirical validation. European Journal of Information Systems, 17(3), 219-235. doi: 10.1057/ejis.2008.12

Yeniçeri, Ö. (2002). Örgütleri etkinleştirme aracı olarak bilgi ve bilgi yönetimi. 2023 Dergisi, 8. [Çevrim-içi: http://www.2023.gen.tr/Arsiv/aralik02/ozcanyenic eri.htm, Erişim tarihi:20 Ocak 2018] 


\section{Ek-1. Bilgi Yönetimi Eğilimi Ölçeği Formu}

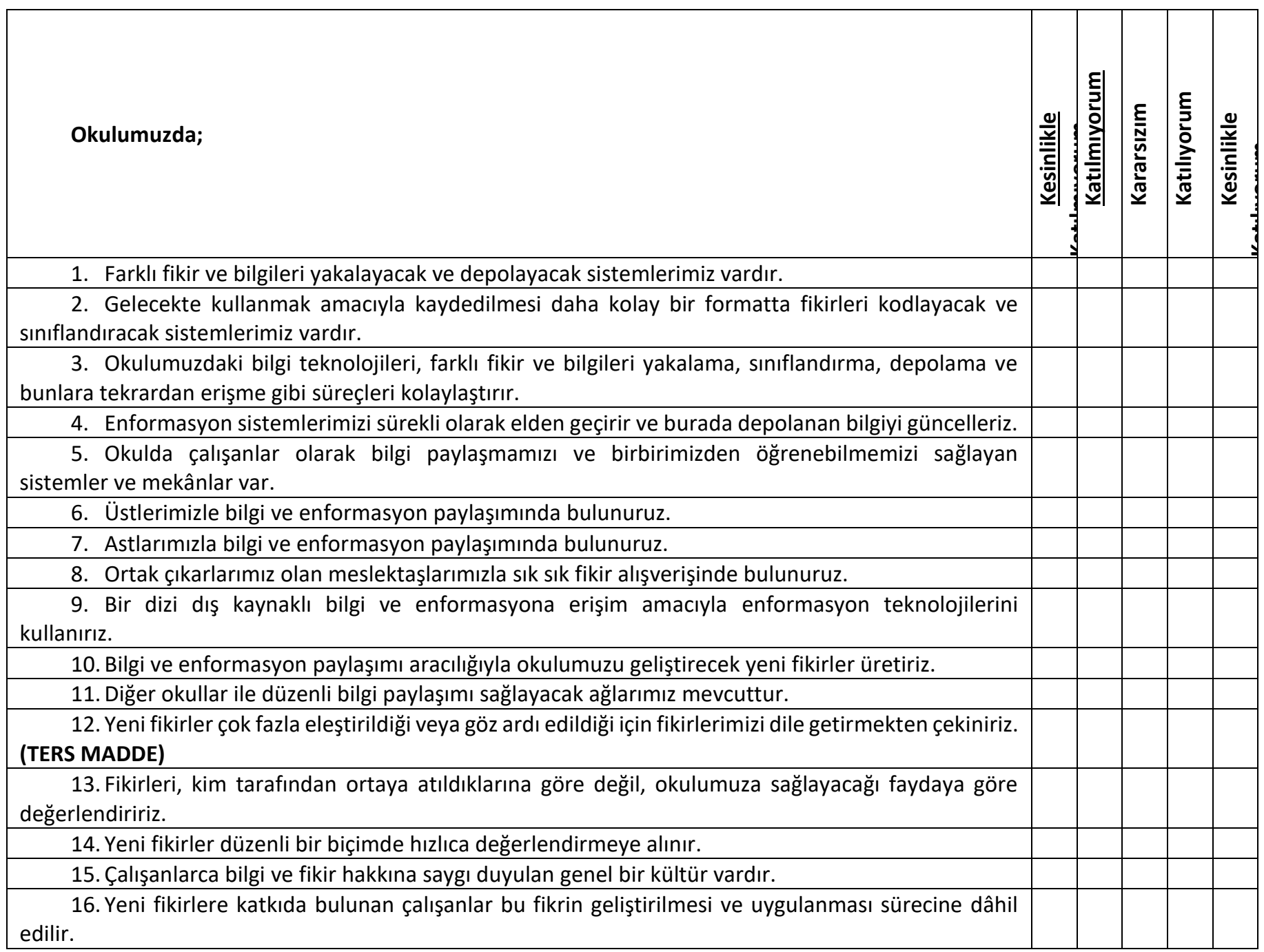

